\title{
Relationship among Energy Consumption, Inflation, Human Capital and Economic Growth:
} Evidence from Indonesia

Mohammed Hadi ${ }^{1}$

George Campbell ${ }^{2 *}$

\begin{abstract}
The main focus of the study was to evaluate the relationship among energy consumption, human capital, inflation and economic growth in the case of Indonesia. The study uses secondary data to conduct the study on Indonesia. The rationale behind selecting the secondary data collection method is to draw the analysis and results on the basis of existing information rather than relying over human perspective of opinions. The data in the study consist of energy consumption, human capital index, GDP per capita and inflation. The time frame that is selected for the collection of data is from 1970 till 2018 which overall makes the time period of 49. The tools that are adopted for conducting the analysis is the unit root test and autoregressive distributed lag (ARDL). The result of the study has revealed that the human capital has a significant influence on the energy consumption of Indonesia. The other elements that are also found to have significant impact are the lag of energy consumption, GDP per capita and lag of GDP per capita. With the higher consumption of energy along with the increasing human capital is significantly and positively influencing the GDP growth of Indonesia.
\end{abstract}

Funding: This study received no specific financial support

Competing Interests: The authors declare that they have no competing interests.

\section{Introduction}

Human capital has different meanings in the contemporary literature. In terms of economics, the human capital can be termed as the labour force possessed by a country, an organisation, or an entity that produces economic value for other individuals (Yao, Ivanovski, Inekwe, \& Smyth, 2019). In the context of business management, human capital can be classified as an intangible asset of skills, knowledge and attributes that are possessed by individuals who work together to create economic value for entire population or the customer base. It is an important asset of a company that helps the company in achieving organisational goals and objectives through creative thinking and synergy (Matthew et al., 2018). Energy consumption is another important concept which has gained prominent over the last decade due to deteriorating natural resources of fuel generation. It has been observed that human capital belonging to recent generations such as Generation $\mathrm{Y}$ are more environment-oriented and have major concern towards sustainability (Bashir, Thamrin, Farhan, Mukhlis, \& Dirta, 2019). Hence, they tend to encourage the use of renewable energy resources with their awareness regarding environment. However, it has been observed that firms in developing countries have not currently adopted the environmental-friendly practices of energy consumption (Ilesanmi \& Tewari, 2017). Indonesia, being a developing country, has an abundance of human capital but the adoption rate of renewable energy consumption is relatively low. In wake of this, the following study aims at studying the association between human capital and energy consumption with empirical evidence from Indonesia. Previously, several studies have evaluated the impact of human capital over economic growth. However, relation between human capital and energy consumption has never been investigated in-depth in existing literature. Therefore, this would be beneficial to bridge the literature gap by contributing the new findings.

It is evident that increase in human capital has prominent impact over the economic development because it possesses the potential to change the production patterns and lead the country towards growth (Salim, Yao, \& Chen, 2017). However, concerning over the environmental prospects and secure the natural resources is essential to achieve the long term growth and success (Alaali, Roberts, \& Taylor, 2015). The energy 
consumption rate in Indonesia continues to increase with every passing year because industrial sector of Indonesia is considered as the driver of their economy and from the period of 1990 till 2016 the growth in energy consumption of Indonesia has reached till $5.39 \%$ including the income per capita, human capital and $\mathrm{CO} 2$ emissions raised to 3.52\%, 1.25\% and 6.11\% respectively (Bashir et al., 2019). Furthermore, in 2016, household energy consumption in Indonesia reached till 348.3 Kilowatt hours per capita that is comparatively high than the rate of 2015 that is 333.3 Kilowatt hours per capita (Statista, 2017). The increase human capital also increases the rate of energy consumption that fuels the different substances and emissions that affects the living environment in a negative way and threatens the human life (Azam, Khan, Zaman, \& Ahmad, 2015; Fang \& Chang, 2016).

In current age, each country around the world is striving for sustainable economic development in order to secure the resources for future generation and stabilise the economic condition of the country as well. The study accumulated by Bojnec and Papler (2011) highlighted that exploitation of natural resources is one of the imperative issues in Indonesia and if the government fails address this issue it can damage the environment of the country in future. In this regard, Indonesia is investing great efforts and financial resources increasing their capacity of renewable power generation and in 2018 renewable power generation capacity of Indonesia has been reached to 9471 megawatts from 9142 megawatts in 2017 (Statista, 2019a).

This underlying study can be highly significant for the government of Indonesia to familiarise them regarding the way rise is human capital has increase the need of energy resources along with the increase energy consumption. In this regard, it is essential to use the renewable energy sources such as solar power, geothermal energy, wind energy, biomass energy and hydropower to address the electricity need of the people as well as protect the environment from harmful hazards. This study will help government authorities of Indonesia to understand the prospects of environmental sustainability and provide the financial assistance and resources to increase the capacity of renewable sources further. Furthermore, the underpinned research can be highly significant for the citizens of the Indonesia to understand the importance of environmental sustainability and contributes their role by using the energy resources in a proper way without wasting it. For this purpose following set of objectives has been designed by researcher.

- To conceptualise the current state of renewable energy consumption in Indonesia.

- To identify and assess factors of human capital that are associated with energy consumption.

- To analyse the impact of human capital on energy consumption in Indonesia.

- To recommend firms within different industries of Indonesia to use renewable energy source with environmentally-aware attitude of human capital.

\section{Literature Review}

The term energy consumption refers to the amount of energy power used for the completion of certain task or objective (Salim et al., 2017). In current era of rapid development where world is advancing towards continuous expansion and growth demand for energy sources has been increased substantially (Bilgili \& Ozturk, 2015). The issue pertaining to energy consumption has always remained as the centre of arguments for researchers to highlight it impact on economic growth and environmental sustainability (Lan, Kakinaka, \& Huang, 2012). However, influence and role of human capital in increasing the rate of energy consumption has always been remain neglected. Increasing energy consumption rate has become the central issues for the developing countries due to the scarcity of resources available (Akram, Jangam, \& Rath, 2019). However, Slaus and Jacobs (2011) advocated that in some developed economies there is significant difference in terms of energy consumption due efficient approaches and measures to implement the energy plants. Statista (2018) stated that per capita energy consumption rate of Germany and Japan are much lower than United States. The energy consumption not only concerns with the electricity energy resources but it also includes water, gas, oil and coal as well and again United States was one of the largest natural gas consumer in 2018 utilizing 817 billion cubic meters (Statista, 2019b). Whereas, Indonesia consumed only 39 billion cubic meters of natural gas in 2018 (Statista, 2019b). US is one of the fastest growing economies having GDP value $\$ 21,427,100$ million in 2019 (CountryEconomy, 2020). Under the assumption that economic development has direct impact over energy consumption it can specify that increasing in production and growth increases the rate of energy consumption as well. In this regard, the study accumulated by Fang and Yu (2020) implies that growth of economic activities requires energy as the mandatory and imperative input to increase the process and rate.

Similarly, Fang and Chen (2017) asserted that scarcity of energy source such as act as the limiting factor for the growth and development of the country because it is the value creating component that increases the production rate to greater extent. However, it is the obvious phenomenon that human capital and work force is the one of the imperative drivers of these production because the increase in rate of human capital substantially increases the production rate by utilising the energy sources (Hamit-Haggar, 2012). Currently, world is moving towards industrialisation that has greatly affected availability of energy sources and resulted in shortage of the natural sources from where energy can be extracted (Sebri \& Ben-Salha, 2014). Bhattacharya, Paramati, Ozturk, and Bhattacharya (2016) high energy consumption rate is not merely threat to the environmental sustainability it also reducing the resources for future prospects. In the study accumulated by Alshehry and Belloumi (2015) identified that electricity consumption was the cause of 
economic growth in Belarus and Bulgaria. Liddle (2014) asserted that human capital is related to energy consumption however economic growth can be considered as the mediating factor of human capital that influences the energy consumption. In this regard, the research assembled by Bashir et al. (2019) implied that growth in Gross domestic product (GDP) of the country indicates that production level in certain state is high and industrial sectors is widely expanded.

H1: There is a significant influence of Human capital on the energy consumption of Indonesia.

In this regard, Ellsmoor (2019) published that, in current era, renewable energy is one of the cheapest sources to generate energy because it just requires the efforts to transform the power from sunrays and wind into productive form. Furthermore, Solar PV power is less expensive than fossil fuels and it does not create any negative impact over the environmental sustainability (Yao et al., 2019). In this regard, Bilgen (2014) asserted that using the new wind and solar plants in the factories and manufacturing plants can help the companies operating in industrial sector to minimise the operating cost. Moreover, some countries such as Norway, China, Japan and Nigeria greatly relies over the foreign countries to import the energy sources to keep the production in their country operational (Statista, 2020). However, it adds to the operating costs and expenditure of the country. In case of renewable energy sources economies are not required to depend over the exporters to build the energy plants in their country and drive their economy.

H2: There is a significant influence of GDP per capita on the energy consumption of Indonesia.

Human capital is considered as the driver of the production of the organisation and plays vital role in increasing the profitability of the company (Tugcu, Ozturk, \& Aslan, 2012). Fei, Dong, Xue, Liang, and Yang (2011) stated that human capital is the principle indicator of economic growth because it possesses the potential to change the production patterns. However, Shahbaz, Khan, and Tahir (2013) asserted that countries having high human capital Index (HCI) have the sustainable economic conditions and possess the valuable skills set. The higher value of HCI can directly influence energy consumption rate because increase in human capital increase the need of energy resources. Akram et al. (2019) highlighted that economic indicators such as GDP, HCI and Inflation rate can help to determine the energy consumption rate of the country by following the assumption that economic growth is the crucial factor of human capital that influences the energy consumption.

H3: There is a significant influence of inflation on the energy consumption of Indonesia.

High human capital and good economic position are beneficial for the development of the country (Boutabba, 2014). However, rise in energy consumption rate can threaten the environmental sustainability and destroy the natural resources for the future generation (Cingano, 2014). In current generation people are greatly emphasising over sustainable environment because rapid expansion industrial sector has damaged the living conditions of the people to greater extent. Tang and Tan (2015) advocated that emission of $\mathrm{CO} 2$ gases is one of the leading cause that has destroyed the green environment to greater extent. Zhang and Lin (2012) asserted that rise in carbon footprint has severely affected the environment in negative way and also destroyed the natural resources of the world. However, some countries have drawn their attention towards the renewable energy sources in order to protect the people of their country and secure the resources for future generation (Inglesi-Lotz, 2016). High energy consumption requires high amount of operating cost that often drags the economies into losses because sometimes cost of energy sources overruns the actual cost (Liddle, 2014). Furthermore, high energy consumption leads to shortage of energy resource and economies are required to import the natural resources to generate the energy (Komal \& Abbas, 2015). However, concept of renewable energy sources such as solar energy, hydro power and wind energy has gain massive popularity in the developed countries having sustainable economic conditions and low energy consumption rate. Shahbaz et al. (2013) advocated that it is not essential that countries having high GDP and HCI value consumes the greater amount of energy because usage of renewable sources has decline the energy consumption rate of the countries.

\section{Methodology}

The study uses secondary data to conduct the study on Indonesia. The rationale behind selecting the secondary data collection method is to draw the analysis and results on the basis of existing information rather than relying over human perspective of opinions. Furthermore, the scope of the topic demands the usage of secondary data because data related to economic conditions of Indonesia such as GDP, INF and HCI cannot be accumulated through primary sources such as interviews or questionnaire surveys. Therefore, secondary data collection method contributed in evaluating the relationship between human capital and energy consumption by investigating the case of Indonesia. For this purpose Quantitative design is selected along with deductive approach and positivism philosophy. Deductive research approach has been used because it permits the researcher to draw the specific conclusion on the general assumptions. Moreover, deductive approach was suitable for underlying research because it permits to draw the relevant findings and theories by testing the broad assumptions. Positivism philosophy has been adopted by the researcher because it permits to evaluate the quantitative information in-depth and unveil the hidden patterns that fuels the further exploration. In this study quantitative research design has been adopted by the researcher because it permits to measure and estimate the extent to which human capital is related with the energy consumption. Qualitative assessment 
limits the researcher to the evaluation of textual information and concepts only and it varies on the basis of human reasons and perspectives. However, Quantitative assessment permits to estimate the relation between independent and dependent variables of the study numerically through statistical calculations.

The data in the study consist of energy consumption, human capital index, GDP per capita and inflation. The variables energy consumption, GDP per capita and inflation is extracted from World Bank database whereas the human capital index data is extracted from Penn World Table database. The time frame that is selected for the collection of data is from 1970 till 2018 which overall makes the time period of 49 . The tools that are adopted for conducting the analysis is the unit root test and autoregressive distributed lag (ARDL).

\subsection{Unit Root Test}

The testing of unit root in the dataset of the variable is critical as it determines as the data is stationary or falls into non-stationary. The traditional method for evaluating the unit root among the data is through the augmented Dickey Fuller (ADF) unit root. The model that is adopted for conducting the ADF is presented below:

$$
\Delta \mathrm{r}_{t}=\lambda_{0}+\lambda_{1} \mathrm{t}+\lambda_{2} \mathrm{r}_{t-1}+\sum_{i=1}^{n} n i 1 \Delta \mathrm{r}_{t-1}+\varepsilon_{t}
$$

With respect to the mode, $\Delta$ is reflected to the change, $n$ denotes the lag whereas $\varepsilon_{t}$ is referred to the random error of stationary that requires adjustments with the autocorrelation error. In the ADF, the null hypothesis is that the data contains unit root which illustrates that it is non-stationary.

\subsection{Autoregressive Distributed Lag (ARDL)}

The ARDL approach function is to measure the cointegration interrelation among the variables where the standard linear function for measuring the interrelation between human capital and energy consumption in Indonesia is provided below:

\section{$E C_{t}=\beta+\theta \mathrm{HC}_{t}+\theta \mathrm{GDP}_{t}+\theta \mathrm{INF}_{t}+\varepsilon_{t}$}

While referring to the model, the variable $\mathrm{HC}_{t}$ is reflected to human capital, $\mathrm{GDP}_{t}$ is denoted as the gross domestic product per capita and $\mathbb{I N F}_{t}$ is recognized as the inflation rate. The variables identified are referred to as regressors of the study whereas referring to $E C_{t}$, it is expressed as the energy consumption which is the regressand and lastly, $\varepsilon_{t}$ represents the usual error term. With respect to examining the long-run cointegration, the ARDL approach is utilized in which it is due to two reasons. The first reason is that ARDL approach can be adopted among the data regardless the data containing unit root or not. Secondly, ARDL approach ignores the low power which respect to identification of cointegration connection. The ECM (error correction model) is applied on the data set:

$$
\begin{aligned}
\Delta E C_{t}=\beta 1+ & \sum_{i=1}^{m 1} \theta_{1 i} \Delta E C_{t-i}+\sum_{j=0}^{n 1} \vartheta_{1 j} \Delta H C_{t-j}+\sum_{j=0}^{n 1} \vartheta_{1 j} \Delta G D P_{t-j}+\sum_{j=0}^{n 1} \vartheta_{1 j} \Delta I N F_{t-j}+\gamma_{1} E C_{t-1} \\
& +\gamma_{2} H C_{t-1}+\gamma_{3} G D P_{t-1}+\gamma_{4} I N F_{t-1}+\varepsilon_{t}
\end{aligned}
$$

With respect to the above model, the null hypothesis indicates that the cointegration interrelation exists between the regressor and regressand which is detected by the F-statistics. If the F-statistics critical value falls below the critical value; then this indicates that the null hypothesis cannot be rejected. Regardless, if the cointegration is identified, then the next process is to conduct the long and short run cointegration where their models are presented below:

$$
\begin{aligned}
& \Delta E C_{t}=\beta 2+\sum_{i=1}^{m 2} \vartheta_{2 i} \Delta E C_{t-i}+\sum_{j=0}^{n 2} \vartheta_{2 j} \Delta H C_{t-j}+\sum_{j=0}^{n 2} \vartheta_{2 j} \Delta G D P_{t-j}+\sum_{j=0}^{n 2} \vartheta_{2 j} \Delta I N F_{t-j}+\varepsilon_{t} \\
& E C_{t}=\beta 3+\sum_{i=1}^{m 3} \vartheta_{3 i} \Delta E C_{t-i}+\sum_{j=0}^{n 3} \vartheta_{3 j} \Delta H C_{t-j}+\sum_{j=0}^{n 3} \vartheta_{3 j} \Delta G D P_{t-j}+\sum_{j=0}^{n 3} \vartheta_{3 j} \Delta I N F_{t-j}+\phi \mu_{t-1}+\varepsilon_{t}
\end{aligned}
$$

The $\phi$ in the above model is reflected to the coefficient error whereas $\mu$ illustrates the negative symbol which indicates as how rapidly the variables are converging.

\section{Results \\ 4.1. Descriptive Statistics}

The summary of the variables on which the data has been collected is provided in Table 1 through the support of the descriptive analysis. The descriptive analysis is conducted through analysing the mean, standard deviation, minimum and maximum value. While referring to energy consumption, its mean value is 
computed as 54.82 which represents that the average amount of energy consumed in Indonesia is $54.82 \%$. While referring the minimum value, it was identified as $24.67 \%$ which is in 1971 whereas the maximum consumption of energy was 68.64 in the period 2015. The dispersion of the data is computed as $12.12 \%$ which indicates that the consumption of energy in Indonesia can either increase or decrease by $12.12 \%$. While examining GDP per capita, its mean value is computed as 1250.29 which indicates the average value of GDP. The maximum GDP per capita of Indonesia was 3893.59 which represents the year 2018 and the minimum value is 79.178 that was in 1970 which indicates that the GDP per capita is significantly growing significantly. The standard deviation is computed as 1216.16 which indicates the dispersion of the GDP per capita.

While referring to Human capital of Indonesia, it is computed as 1.95 which is closer to 2 indicates that the human capital in the country is good. The minimum value identified for human capital is 1.354 which was in 1970 whereas the highest point of human capital is 2.435 that is indicated in 2018; therefore, this indicates that the human capital of Indonesia has significantly improved. The standard deviation of human capital is computed as 0.367 which indicates the level of human capital that can either increase or decrease. Lastly, while evaluating the inflation rate of Indonesia, the mean value is computed as $11.01 \%$ which indicates a high average point of inflation. The maximum value computed for inflation is $58.45 \%$ which was at the period 1998 in which the Asian financial crises occurred. The minimum value of inflation is 3.198 is at 2018 that signifies that Indonesia has significantly reduced its inflation rate in the current years. The dispersion of the standard deviation is computed as 9.780; this shows that it can increase or decrease by 9.780 .

Table-1. Descriptive analysis.

\begin{tabular}{c|c|c|c|c}
\hline & Energy Consumption & GDP per Capita & Human Capital & Inflation \\
\hline Mean & 54.823 & 1250.298 & 1.952 & 11.01 \\
\hline Maximum & 68.643 & 3893.596 & 2.435 & 58.45 \\
\hline Minimum & 24.67 & 79.178 & 1.354 & 3.198 \\
\hline Std. Dev. & 12.12 & 1216.167 & 0.367 & 9.780 \\
\hline
\end{tabular}

\subsection{Unit Root Test}

The unit root test is applied on the data set in which the main aim of the test is to reveal as where the data contains the unit root that further signifies as whether the data is stationary or not stationary. Thus, the null hypothesis of the unit root test is that the unit root is present in the data. The results of ADF unit root among the dataset of the study can be evaluated in Table 2 in which the t-statistics along with the probability is indicated. The variable energy consumption, human capital, GDP per capita and inflation has the t-statistics of $-4.284[\mathrm{p}=0.001],-1.539[\mathrm{p}=0.504], 0.427[\mathrm{p}=0.982]$ and $4.798[\mathrm{p}=0.000]$, respectively. On this basis it can be indicated that energy consumption and inflation variables are stationary and does not have unit root present. On the other hand, human capital and GDP per capita contains unit root and thus are non-stationary.

\begin{tabular}{c|c|c}
\hline \multicolumn{3}{|c}{ Table-2. ADF unit root. } \\
\hline ADF Test & T-Statistics & Prob. \\
\hline Energy Consumption & -4.284 & 0.001 \\
\hline Human Capital & -1.539 & 0.504 \\
\hline GDP Per Capita & 0.427 & 0.9821 \\
\hline Inflation & 4.798 & 0.000 \\
\hline
\end{tabular}

4.3. ARDL

On the basis of the ADF unit root, it was identified that few variables has unit root present on the time series data; therefore, the ARDL approach is conducted for evaluating the causality among the factors. The study of Lau, Yii, Lee, Chong, and Lee (2018) has indicated that ARDL approach is useful for predicting the future values with respect to the iterative values. Table 3 reflects on the results of ARDL in which the energy consumption represents the regressand or dependent variable whereas the other variables are the regressors. While referring the significance of model, the prob (F-statistic) element is evaluated in which the value is computed as 0.000 which is lower than the threshold of $1 \%$; therefore, this implies that the model generated through ARDL is significant and is not generated due to statistical errors. With respect to the R-square value, it is computed as $98.9 \%$ which shows that the regressors are able to interpret or explain the variance of energy consumption by $98.9 \%$. Moving to the main results, it is found that the lag of energy consumption, GDP per capita, lag of GDP per capita and human capital has a significant influence on the energy consumption. With every unit change on lag of energy consumption, lag of GDP per capita and human capital will result in a positive change to energy consumption with respect to coefficient of $0.863,0.002$ and 3.206. On the other hand, GDP per capita would result in an adverse effect with the value change of -0.002 to energy consumption. Lastly, inflation is found to have insignificant influence on the energy consumption. Therefore, it can be indicated that human capital plays a significant role towards the energy consumption of. 
Table-3. ARDL Results

\begin{tabular}{l|c|c|c|c}
\hline Variable & Coefficient & Std. Error & t-Statistic & Prob.* \\
\hline ENERGY_CONSUMPTION(-1) & $0.863^{* * *}$ & 0.048 & 17.983 & 0.000 \\
\hline GDP_PER_CAPITA & $-0.002^{* * *}$ & 0.000 & -3.089 & 0.003 \\
\hline GDP_PER_CAPITA(-1) & $0.002^{* * *}$ & 0.000 & 2.862 & 0.006 \\
\hline HUMAN_CAPITAL & $3.206 *$ & 1.639 & 1.955 & 0.057 \\
\hline INFLATION & -0.0119 & 0.016 & -0.700 & 0.487 \\
\hline C & 2.5574 & 1.241 & 2.0607 & 0.046 \\
\hline R-squared & $98.9 \%$ & F-statistic & 773.498 & \\
\hline Adjusted R-squared & $98.7 \%$ & Prob(F- & & 0 \\
statistic) & &
\end{tabular}

4.4. Analysing Hypothesis

\begin{tabular}{l|l|c|c|c}
\hline T. & Description & Beta & Significance & Result \\
\hline H1 & $\begin{array}{l}\text { There is a significant influence of Human } \\
\text { capital on the energy consumption of } \\
\text { Indonesia }\end{array}$ & Co $=3.206$ & $\mathrm{P}=0.057$ & Accepted \\
\hline H2 & $\begin{array}{l}\text { There is a significant influence of GDP per } \\
\text { capita on the energy consumption of } \\
\text { Indonesia }\end{array}$ & Co $=-0.002$ & $\mathrm{P}=0.006$ & Accepted \\
\hline H3 & $\begin{array}{l}\text { There is a significant influence of inflation on } \\
\text { the energy consumption of Indonesia }\end{array}$ & $\mathrm{Co}=-0.0119$ & 0.487 & Rejected \\
\hline
\end{tabular}

\section{Discussion}

The core aim of the study was to evaluate the influence of human capital on the energy consumption of Indonesia where the secondary data has been gathered and the statistical tool ARDL is conducted for evaluating the results. The results have revealed that the human capital has a significant and positive influence to the energy consumption of Indonesia. Similarly the study conducted by Akram et al. (2019) has illustrated that the human capital influences on the economic growth that further affects the energy consumption of a country. The improvement of the high human capital and good economic position are beneficial for the overall country (Boutabba, 2014). Furthermore, from the descriptive analysis, it was indicated that the human capital of Indonesia is significantly improving over the years which further aided in its growth to its economy which can be reflected to the increase of GDP. Moreover, the findings have also revealed that the GDP growth adversely influences on the energy consumption which can indicate that Indonesia is required to consume its energy for the purpose of improving its GDP growth. Similarly, the study conducted Alshehry and Belloumi (2015) has indicated that the electricity consumption can overall lead towards economic growth; however, the consumption of material and resources can also affect the environmental sustainability.

\section{Conclusion}

The main focus of the study was to evaluate the influence of human capital on the energy consumption of Indonesia. Human capital is defined as the labour force of a country or organization that creates the economic value. It is understandable that the human capital has an influence on the economic development of the country; however, the area of how human capital impacts on the energy consumption remains to be unidentified particularly in Indonesia. Thus, the study seeks to evaluate the influence of human capital in which the secondary data is collected for 49 years' time frame where the statistical technique is incorporated for revealing the findings. The result of the study has revealed that the human capital has a significant influence on the energy consumption of Indonesia. The other elements that are also found to have significant impact are the lag of energy consumption, GDP per capita and lag of GDP per capita. The results of the study can illustrate that with the growing of human capital of Indonesia is also leading to a higher consumption of energy. With the higher consumption of energy along with the increasing human capital is significantly and positively influencing the GDP growth of Indonesia.

\section{Limitations and Future Implications}

With respect to the limitation of the study, it is purely focused on Indonesia which is the Asian country. Therefore, in this perspective, the future studies can be conducted among different Asian countries such as Malaysia, India, Pakistan, Russia or others. Furthermore, there are only few metrics that were considered in the study which are GDP per capita, Inflation and human capital; however, in future studies, other elements can be included such as interest rate, unemployment or other factors. Furthermore, with respect to limitations, 
due to limited available data through secondary sources has led towards obtaining limited sample of years. Thus, the increase of sample years can increase the robustness of the study.

\section{References}

Akram, V., Jangam, B. P., \& Rath, B. N. (2019). Does human capital matter for reduction in energy consumption in India? International Journal of Energy Sector Management, 12(2), 359-376. Available at: https://doi.org/10.1 108/IJESM07-2018-0009.

Alaali, F., Roberts, J., \& Taylor, K. (2015). The effect of energy consumption and human capital on economic growth: An exploration of oil exporting and developed countries. SERPS (Sheffield Economics Research Papers Series), (015).

Alshehry, A. S., \& Belloumi, M. (2015). Energy consumption, carbon dioxide emissions and economic growth: The case of Saudi Arabia. Renewable and Sustainable Energy Reviews, 41, 237-247.Available at: https://doi.org/10.1016/j.rser.2014.08.004.

Azam, M., Khan, A. Q., Zaman, K., \& Ahmad, M. (2015). Factors determining energy consumption: Evidence from Indonesia, Malaysia and Thailand. Renewable and Sustainable Energy Revierws, 42, 1123-1131.Available at: https://doi.org/10.1016/j.rser.2014.10.061.

Bashir, A., Thamrin, K. H., Farhan, M., Mukhlis, M., \& Dirta, P. A. (2019). The causality between human capital, energy consumption, $\mathrm{CO} 2$ emissions, and economic growth: Empirical evidence from Indonesia. International Journal of Energy Economics and Policy, 9(2), 98-104.

Bhattacharya, M., Paramati, S. R., Ozturk, I., \& Bhattacharya, S. (2016). The effect of renewable energy consumption on economic growth: Evidence from top 38 countries. Applied Energy, 162, 733-741.Available at: https://doi.org/10.1016/j.apenergy.2015.10.104.

Bilgen, S. (2014). Structure and environmental impact of global energy consumption. Renewable and Sustainable Energy Revieres, 38, 890-902.Available at: https://doi.org/10.1016/j.rser.2014.07.004.

Bilgili, F., \& Ozturk, I. (2015). Biomass energy and economic growth nexus in G7 countries: Evidence from dynamic panel data. Renewable and Sustainable Energy Reviews, 49, 132-138.Available at: https://doi.org/10.1016/j.rser.2015.04.098.

Bojnec, Š., \& Papler, D. (2011). Economic efficiency, energy consumption and sustainable development. Journal of Business Economics and Management, $12(2), 353-374$.

Boutabba, M. A. (2014). The impact of financial development, income, energy and trade on carbon emissions: Evidence from the Indian economy. Economic Modelling, 40, 33-41.Available at: https://doi.org/10.1016/j.econmod.2014.03.005.

Cingano, F. (2014). Trends in income inequality and its impact on economic growth

CountryEconomy. (2020). United States (USA) GDP - gross domestic product 2019, countryeconomy.com. Retrieved from: https://countryeconomy.com/gdp/usa. [Accessed 6 March 2020].

Ellsmoor, J. (2019). Renewable energy is now the cheapest option - even without subsidies, Forbes. Retrieved from: https://www.forbes.com/sites/jamesellsmoor/2019/06/15/renewable-energy-is-now-the-cheapest-optioneven-without-subsidies/\#6d1a47835a6b. [Accessed 6 March 2020].

Fang, Z., \& Chang, Y. (2016). Energy, human capital and economic growth in Asia Pacific countries-Evidence from a panel cointegration and causality analysis. Energy Economics, 56, 177-184.Available at: https://doi.org/10.1016/j.eneco.2016.03.020.

Fang, Z., \& Chen, Y. (2017). Human capital and energy in economic growth-Evidence from Chinese provincial data. Energy Economics, 68, 340-358.Available at: https://doi.org/10.1016/j.eneco.2017.10.007.

Fang, Z., \& Yu, J. (2020). The role of human capital in energy-growth nexus: An international evidence. Empirical Economics, 58(3), 1225-1247.Available at: https://doi.org/10.1007/s00181-018-1559-8.

Fei, L., Dong, S., Xue, L., Liang, Q., \& Yang, W. (2011). Energy consumption-economic growth relationship and carbon dioxide emissions in China. Energy Policy, 39(2), 568-574.Available at: https://doi.org/10.1016/j.enpol.2010.10.025.

Hamit-Haggar, M. (2012). Greenhouse gas emissions, energy consumption and economic growth: A panel cointegration analysis from Canadian industrial sector perspective. Energy Economics, 34(1), 358-364.Available at: https://doi.org/10.1016/j.eneco.2011.06.005.

Ilesanmi, K. D., \& Tewari, D. D. (2017). Energy consumption, human capital investment and economic growth in South Africa: A vector error correction model analysis. OPEC Energy Review, 41(1), 55-70.Available at: https://doi.org/10.1111/opec.12094.

Inglesi-Lotz, R. (2016). The impact of renewable energy consumption to economic growth: A panel data application. Energy Economics, 53, 58-63.Available at: https://doi.org/10.1016/j.eneco.2015.01.003.

Komal, R., \& Abbas, F. (2015). Linking financial development, economic growth and energy consumption in Pakistan. Renewable and Sustainable Energy Reviews, 44, 21 1-220.Available at: https://doi.org/10.1016/j.rser.2014.12.015.

Lan, J., Kakinaka, M., \& Huang, X. (2012). Foreign direct investment, human capital and environmental pollution in China. Environmental and Resource Economics, 51(2), 255-275.Available at: https://doi.org/10.1007/s 10640-011-9498-2.

Lau, L. S., Yii, K. J., Lee, C. Y., Chong, Y. L., \& Lee, E. H. (2018). Investigating the determinants of renewable energy consumption in Malaysia: AN ARDL approach. International Journal of Business \& Society, 19(3), 886-903.

Liddle, B. (2014). Impact of population, age structure, and urbanization on carbon emissions/energy consumption: evidence from macro-level, cross-country analyses. Population and Environment, 35(3), 286-304.Available at: https://doi.org/10.1007/s11111-013-0198-4.

Matthew, O., Ede, C. U., Osabohien, R., Ejemeyovwi, J. O., Fasina, F., \& Akinpelumi, D. (2018). Electricity consumption and human capital development in Nigeria: Exploring the implications for economic growth. International Journal of Energy Economics and Policy, 8(6), 8-15. 
Salim, R., Yao, Y., \& Chen, G. S. (2017). Does human capital matter for energy consumption in China? Energy Economics, 67, 49-59.Available at: https://doi.org/10.1016/j.eneco.2017.05.016.

Sebri, M., \& Ben-Salha, O. (2014). On the causal dynamics between economic growth, renewable energy consumption, $\mathrm{CO} 2$ emissions and trade openness: Fresh evidence from BRICS countries. Renewable and Sustainable Energy Reviews, 39, 14-23.Available at: https://doi.org/10.1016/j.rser.2014.07.033.

Shahbaz, M., Khan, S., \& Tahir, M. I. (2013). The dynamic links between energy consumption, economic growth, financial development and trade in China: fresh evidence from multivariate framework analysis. Energy Economics, 40, 821.Available at: https://doi.org/10.1016/j.eneco.2013.06.006.

Slaus, I., \& Jacobs, G. (2011). Human capital and sustainability. Sustainability, 3(1), 97-154.Available at: https://doi.org/10.3390/su3010097.

Statista. (2017). Indonesia- household electricity consumption per capita 2016 Statista (2020). Retrieved from https://www.statista.com/statistics/598007/household-consumption-of-electricity-per-capita-in-indonesia/. [Accessed 6 March 2020].

Statista. (2018). Topic: Global energy consumption (2020). Retrieved from https://www.statista.com/topics/4042/globalenergy-consumption/. [Accessed 6 March 2020].

Statista. (2019a). Indonesia: Renewable power generation capacity 2008-2018 | Statista (2020). Retrieved from https://www.statista.com/statistics/872498/total-renewable-power-generation-capacity-in-indonesia/. [Accessed 6 March 2020].

Statista. (2019b). World natural gas consumption by country 2018 Statista (2020). Retrieved from https://www.statista.com/statistics/265407/world-natural-gas-consumption-by-country/. [Accessed 6 March 2020].

Statista. (2020). UK: Oil and gas imports, by country. Retrieved from https://www.statista.com/statistics/381963/crudeoil-and-natural-gas-import-origin-countries-to-united-kingdom-uk/. [Accessed: 6 March 2020].

Tang, C. F., \& Tan, B. W. (2015). The impact of energy consumption, income and foreign direct investment on carbon dioxide emissions in Vietnam. Energy, 79, 447-454.Available at: https://doi.org/10.1016/j.energy.2014.11.033.

Tugcu, C. T., Ozturk, I., \& Aslan, A. (2012). Renewable and non-renewable energy consumption and economic growth relationship revisited: Evidence from G7 countries. Energy Economics, 34(6), 1942-1950.Available at: https://doi.org/10.1016/j.eneco.2012.08.021.

Yao, Y., Ivanovski, K., Inekwe, J., \& Smyth, R. (2019). Human capital and energy consumption: Evidence from OECD countries. Energy Economics, 84, 104534.Available at: https://doi.org/10.1016/j.eneco.2019.104534.

Zhang, C., \& Lin, Y. (2012). Panel estimation for urbanization, energy consumption and $\mathrm{CO} 2$ emissions: A regional analysis in China. Energy policy, 49(C), 488-498.Available at: https://doi.org/10.1016/j.enpol.2012.06.048. 